\title{
Relation of Polypharmacy to Systemic and Oral Health Related Factors
}

\author{
MADALINA BICHERU ${ }^{1}$, CRISTINA TEODORA PREOTEASA ${ }^{1 *}$, ANDREEA ZAMFIRESCU ${ }^{1,2}$, ANA CAPISIZU1,2, \\ MARINA MELESCANU IMRE ${ }^{1}$, ELENA PREOTEASA ${ }^{1}$ \\ ${ }^{1}$ Carol Davila University of Medicine and Pharmacy, 8 Eroilor Sanitari Blvd., 050474, Bucharest, Romania \\ ${ }^{2}$ The Hospital for Chronic Diseases St. Luca, 2 Berceni Road, 041915, Bucharest, Romania
}

To assess polypharmacy (i.e., multiple medication use, as synthetic chemical products) and its relationship to general, systemic health and oral health factors in adults over 50 years old. A cross-sectional study was conducted on a convenience sample of adult patients recruited from two medical centers from Bucharest, i.e. from the Clinic of Dental Prosthetics, Carol Davila University of Medicine and Pharmacy, and from Saint Luca Hospital for Chronic Diseases. Study sample included 126 patients, that used a mean of 5.2 drugs. Almost half of patients (43.65\%) used more than five prescribed medications. There was a tendency to use a greater number of medications in the case of patients that were hospitalized at Saint Luca Hospital, were less educated, had a lower income, had a greater number of comorbidities, had untreated edentulism in both jaws, were unfrequently wearing removable prosthesis and were using denture adhesives. Both positive and negative effects of polypharmacy should be considered in mutimorbidity patients when establishing prescription medications, along with general and oral factors that may influence treatment conduct and outcome.

Keywords:medication, drug, ageing, edentulism, dental prosthesis

Aging often associates comorbidities that require multiple medications. Nowadays beside the trend of aging population, a trend of increasing prescription drug use and polypharmacy can also be observed [1]. Polypharmacy due to multimorbidity is most common in older population, and should be considered by all healthcare providers. Polypharmacy may results in drug-drug interactions with side effects that may contribute to further deterioration of health status, may result in medication nonadherence, leading to higher health care costs [2]. Thereforealthough polypharmacy can be clinically justified, it can also be sometimes inappropriate, it being seen as an issue that requires in-depth knowledge in order to define the best parameters of managing it [3]. This is a phenomenon in which both physicians and patients pay an important role, needing to be analyzed in a wider context, including not only health related factors, but also behavioral, social, cultural and geographical ones [17-21].

The aim of this study was to assess polypharmacy (i.e., multiple medication use), and its relationship to general, systemic health and oral health factors in adults over 50 years old.

\section{Experimental part \\ Method}

A cross-sectional study was conducted on a convenience sample of adult patients. Participants were recruited from two medical centers from Bucharest, from the Clinic of Dental Prosthetics of the Carol Davila University of Medicine and Pharmacy, and from the Saint Luca Hospital for Chronic Diseases. Only adults over 50 years of age, without severe cognitive impairment,were included. Patients were included after giving an informed consent to attend this study.

Main study variables were patients general characteristics (sex, age, education, income), general health status assessed by the number of comorbidities, medication used assessed by the number of drugs taken, and some features of oral status (presence of complete edentulism in one or both jaws, prosthetic treatment, wearing of removable prosthesis, and use of denture adhesives). Data was collected by interviews, examination of medical records and clinical oral examination.

Data analysis was conducted after assessing the normality of the distribution of the variables, which lead to the usage of nonparametric tests. For the comparison of two independent groups the Mann W hitney test was used, for the comparison of more than two independent groups the Kruskal-Wallis test was used, and for correlations the Spearman test was used. Statistical significance was considered at ap-value $<0.05$. The data were analyzed with SPSS Statistics software.

\section{Results and discussions}

Study sample included 126 patients, from which 51 patients form the Clinic of Dental Prosthetics of the Carol Davila University of Medicine and Pharmacy, and 75 hospitalized patients from Saint Luca Hospital for Chronic Diseases.

The included patients, at the time of data collection, used a mean of 5.2 drugs, with a minimum of 0 drugs, and a maximum of 15 drugs. The majority of patients used multiple medications, and $43,65 \%$ used more than five prescribed medications (table 1 ).

\begin{tabular}{|c|c|c|}
\hline No of drugs used & Frequency & Percent \\
\hline$<1$ & 7 & 5.6 \\
\hline 2 & 10 & 79 \\
\hline 3 & 12 & 9.5 \\
\hline 4 & $20^{-}$ & 15.9 \\
\hline 5 & 22 & 17.5 \\
\hline 6 & $20^{-}$ & 159 \\
\hline 7 & 15 & 11.9 \\
\hline 8 & 9 & 7.1 \\
\hline$>9$ & $11^{-}$ & 8.7 \\
\hline
\end{tabular}

Table 1

NUMBER OF MEDICATIONS USED IN THE STUDY SAMPLE 


\begin{tabular}{|c|c|c|c|}
\hline \multicolumn{2}{|l|}{ Variable } & \multirow{2}{*}{$\begin{array}{l}\text { No of drugs } \\
\text { used (mean) } \\
5.33\end{array}$} & \multirow{2}{*}{$\begin{array}{c}\mathbf{p} \\
0.692\end{array}$} \\
\hline $\operatorname{sex}$ & male & & \\
\hline & female & 4.93 & \\
\hline \multirow[t]{4}{*}{ age } & $50-60$ years & 4.11 & 0.265 \\
\hline & $61-70$ years & $5.11^{-}$ & \\
\hline & $71-80$ years & 5.49 & \\
\hline & $81-90$ years & 5.56 & \\
\hline \multirow[t]{2}{*}{ recruited } & Hospital for Chronic Diseases & 6.11 & $<0.001^{*}$ \\
\hline & Clinic of Dental Prosthetics & 3.86 & \\
\hline \multirow[t]{3}{*}{ education } & primary/middle school(I-VIII) & 6.04 & $0.003^{*}$ \\
\hline & high school diploma & $4.70^{\circ}$ & \\
\hline & bachelor's degree & 4.09 & \\
\hline \multirow[t]{3}{*}{ income } & $<500 \mathrm{RON}$ & 5.87 & $0.013^{*}$ \\
\hline & $500-1500 \mathrm{RON}$ & 4.59 & \\
\hline & $>1500 \mathrm{RON}^{-}$ & 4.17 & \\
\hline
\end{tabular}

Table 3

NUMBER OF MEDICATIONS USED ACCORDING TO NUMBER OF COMORBIDITIES

\begin{tabular}{|l|c|c|}
\hline No of comorbidities & No of drugs used (mean) & p \\
\hline$<1$ & 0.67 & $<0.001^{*}$ \\
\hline 2 & $2.64^{-}$ & \\
\hline 3 & $3.68^{-}$ & \\
\hline 4 & $5.37^{-}$ & \\
\hline 5 & $6.11^{-}$ & \\
\hline 6 & $6.75^{-}$ & \\
\hline$>7$ & $8.67^{-}$ & \\
\hline
\end{tabular}

Analyzing the relationship between polypharmacy and general characteristics, there was noticed the tendency to use a greater number of medications by patients that were hospitalized at Saint Luca Hospital for Chronic Diseases, were less educated and had a lower income (table 2).

Analyzing the relationship between polypharmacy and systemic status, a strong relationship was noted between the number of comorbidities and number of drugs used, as by conducting a subgroup analysis (table 3 ) or correlation analysis $(r=0.764 ; p<0.001 *)$.

Analyzing the relationship between polypharmacy and oral status, there was a tendency to use a greater number of medications by patients with untreated edentulism in both jaws, who were unfrequently wearing the removable prostheses and who were using denture adhesives (table 4).

This study's main results suggest that polypharmacy is frequently encountered in adult patients over 50 years old. We observed a trend to use a greater number of medications by patients recruited from Saint Luca Hospital for Chronic Diseases, were less educated, had a lower income, a greater number of comorbidities, untreated edentulism in both jaws, wereunfrequently wearingthe removable prostheses and used denture adhesives.

Especially in the elderly, multimorbidity defined by coexistence of multiple chronic conditions, is frequently encountered and often relates to polypharmacy [4]. In this context polypharmacy is completely justifiable from a medical point of view, but raises concerns for physicians especially, such as unwanted side effects and drug-drug interactions, with possible negative impact on health and treatment outcome. For example, in patients with multimorbidity and polypharmacy the dentist should consider the higher risk of occurrence of xerostomia and hyposialia, a common side effect associated with many pharmacological drug classes [5]. These changes may be a risk factor for some oral conditions as denture stomatitis and oral candidiasis, with a negative effecton the patient's comfort and quality of life, and may influence treatment outcome $[6,7]$. Therefore an accurate evaluation of medications used should be considered during initial evaluation.

By this study results, polypharmacy is frequently encountered and relates strongly to the number of comorbidities, but also to other factors. These results are partially in accordance with other research. The differences that are noted are linked to several factors, e.g., different geographic origin of study sample, different characteristics of study sample such as age distribution, different interpretation of polypharmacy (i.e. it is defined as the use of multiple medications, but there is no consensus on the cut-off value), other determinants of polypharmacy considered.

Among previous studies, polypharmacy registers a different frequency. Polypharmacy defined by the regular use of five or more drugs was encountered with a frequency of $11.8 \%$ in adults aged $40-81$ years old in the population of Lausanne, Switzerland [8]. A recent study on the US population stated that half of the patients taking prescription drugs are exposed to two or more drugs, and $5 \%$ are exposed to 8 or more [9]. Another study on the US population revealed that among adults above 65 years old $40.6 \%$ used multiple drugs and $35.6 \%$ had polypharmacy (defined as use of more than five medications), of which about $57 \%$ had contraindicated drug combinations [10]. Our results are partially similar, with regards to confirming the increasing frequency of polypharmacy.

\begin{tabular}{|c|c|c|c|}
\hline \multicolumn{2}{|l|}{ Variable } & \multirow{2}{*}{$\begin{array}{c}\text { No of drugs } \\
\text { used (mean) } \\
4.87\end{array}$} & \multirow{2}{*}{$\begin{array}{c}\mathbf{p} \\
0.084\end{array}$} \\
\hline edentulism & complete edentulism in both jaws & & \\
\hline & complete edentulism in one jaw & 4.75 & \\
\hline & dentate in both jaws & 5.66 & \\
\hline \multirow[t]{3}{*}{ prosthetic status } & without prosthetic rehabilitation in both jaws & 6.13 & $0.003^{*}$ \\
\hline & without prosthetic rehabilitation in one jaw & 3.75 & \\
\hline & with prosthetic rehabilitation & 4.81 & \\
\hline \multirow{3}{*}{$\begin{array}{l}\text { removable } \\
\text { prostheses use }\end{array}$} & always & 4.21 & $0.033^{*}$ \\
\hline & socially & 5.46 & \\
\hline & never & 6.00 & \\
\hline $\begin{array}{l}\text { denture } \\
\text { adhesives }\end{array}$ & $\begin{array}{l}\text { yes } \\
\text { no } \\
\text { do not lnow what represents }\end{array}$ & $\begin{array}{l}5.47 \\
4.07 \\
3.00\end{array}$ & $0.029 *$ \\
\hline
\end{tabular}

Table 4

NUMBER OF MEDICATIONS USED ACCORDING TO GENERAL CHARACTERISTICS 
In previous research, advanced age was usually found to be associated with an increased frequency of polypharmacy [8]. This tendency was also noted in this research but did not reach statistical significance, one contributing factor being the relatively small sample size.

Similar to other research [8], this study's results suggest that polypharmacy is more frequent in individuals with lower education. One explanation may be that less educated persons expect more positive results from medication, withoutbalancing with the negative side effect they bring and drug-to-drug interactions [11]. The effect of education is perceived as controversial. Even so its impact most probably exists, as generally influencing health status and treatment accessibility. Other studies found different relationships between the two $[10,12,13]$.

As there is a clearly accepted relationship between complete edentulism and other coexisting diseases [14], the increased frequency of polypharmacy with completely edentulous patients, especially in those without prosthetic rehabilitation, found in this research comes as no surprise. According to our study, patients that use dental adhesive register a tendency to use more medications, which probably relates to their habit of using and investing more in medications in general.

Poypharmacy in elderly should be carefully analyzed, as previously being stated that nearly half of older adults take one or more medications that are not medically necessary [15]. By some former evidence, non-institutionalized patients are on significantly less drugs, and also it seem the medication is controlled better in some residencies as geriatric clinics,being observed to exert a positive effect on polypharmacy as associating a substantial reduction of prescribed drugs [16]. Even if it is difficult to generalize for all nursing homes for elderly in this regard, it might be a good fact to point-out to the medical staff from these residency the recommendation to reassess medication and if possible to decrease the number of drugs administered, as their patients are old, frequently with multiple systemic diseases and probable frequently register polypharmacy.

Among study limitations the following can be mentioned: the relatively small sample size, the relative small number of systemic and oral factors analyzed that may affect the number of medications used, and in general the difficulty to assess a complexphenomenon as polypharmacy.

\section{Conclusions}

Polypharmacy is frequently encountered in adult patients over 50 years of age. We noticed a trend to use a greater number of medications by patients that were recruited from the Hospital for Chronic Diseases, were less educated, had a lower income, a greater number of comorbidities, untreated edentulism in both jaws, wereunfrequently wearing of removable prostheses and used denture adhesives. Both positive and negative effects of polypharmacy should be considered in mutimorbid patients when establishing prescription medications, along with general and oral factors that may influence treatment conduct and outcome.

\section{References}

1. KANTOR ED, REHM CD, HAAS JS, CHAN AT, GIOVANNUCCI EL. Trends in Prescription Drug Use among Adults in the United States from 1999-2012. JAMA. 2015;314(17):1818-1831.

2. CHARLESW ORTH CJ, SMIT E, LEE DSH, ALRAMADHAN F, ODDEN MC. Polypharmacy Among Adults Aged 65 Years and Older in the United States: 1988-2010. The J ournals of Gerontology Series A: Biological Sciences and Medical Sciences. 2015;70(8):989-995.
3. BURT J , ELMORE N, CAMPBELL SM, RODGERS S, AVERY AJ, PAYNE RA. Developing a measure of polypharmacy appropriateness in primary care: systematic review and expert consensus study. BMC Medicine. 2018;16:91.

4. KOBERLEIN J, GOTTSCHALL M, CZARNECKI K, THOMAS A, BERGMANN A, VOIGT K. General practitioners' views on polypharmacy and its consequences for patient health care. BMC Family Practice. 2013;14:119.

5. DONATH F, TONNER F, CHAVDA R, GATIGNOL J, BOUYRIE J. Randomized trial of the efficacy and safety of a new oral spray for druginduced xerostomia. Clinical and Experimental Dental Research. 2016;2(2):112-120. .

6. PREOTEASA E, TÂNCU A, IOSIF L, MELESCANU IMRE M, MURARIUMÃGUREANU C, PREOTEASA C. Salivary changes related to systemic diseases in the edentulous patients. J ournal of Medicine and Life. 2014;7(4):577-580.

7. PREOTEASA CT, SULTAN AN, POPA L, GHICA MV, IONESCU E, TANCU AMC, PREOTEASA E. Studies regarding the wettability of acrylic and silicone dental materials. Farmacia. 2011;59(6):871-878.

8. CASTIONI J, MARQUES-VIDAL P, ABOLHASSANI N, VOLLENWEIDER $P$, WAEBER G. Prevalence and determinants of polypharmacy in Switzerland: data from the CoLaus study. BMC Health Services Research. 2017;17:840.

9. QUINN KJ, SHAH NH. A dataset quantifying polypharmacy in the United States. Scientific Data. 2017;4:170167. doi:10.1038/sdata.2017.167. 10. GOLCHIN N, FRANK SH, VINCE A, ISHAM L, MEROPOL SB. Polypharmacy in the elderly. J ournal of Research in Pharmacy Practice. 2015;4(2):85-88.

11. CT PREOTEASA, A DUMITRACHE, M ENACHE, L IOSIF, E PREOTEASA. Patient's Information on Medical Aspects, Romanian Journal of Oral Rehabilitation 10 (1), 36-40.

12. PAPPA E, KONTODIMOPOULOSN, PAPADOPOULOSAA, TOUNTAS $Y$, NIAKASD. Prescribed-drug utilization and polypharmacy in a general population in Greece: association with sociodemographic, health needs, health-services utilization, and lifestyle factors. Eur J Clin Pharmacol. 2011 Feb;67(2):185-92.

13. WAUTERS M, ELSEVIERS M, VAES B, DEGRYSE J, DALLEUR O, VANDER STICHELE R, VAN BORTEL L, AZERMAI M. Polypharmacy in a Belgian cohort of community-dwelling oldest old (80+) Acta Clin Belg. 2016;71(3):158-166.

14. FELTON DA. Complete Edentulism and Comorbid Diseases: An Update. J Prosthodont. 2016 Jan;25(1):5-20.

15. MAHER RL, HANLON JT, HAJJAR ER. Clinical Consequences of Polypharmacy in Elderly. Expert opinion on drug safety. 2014;13(1):10. 16. KRUSE W, RAMPMAIER J , FRAUENRATH-VOLKERS C, VOLKERT D, WANKMÜLLER I, MICOL W, OSTER P, SCHLIERF G. Drug-prescribing patterns in old age. A study of the impact of hospitalization on drug prescriptions and follow-up survey in patients 75 years and older.

17. MATEI,M.N., EARAR, K., TRINCA,L.C., Degradation characteristics of poly-tetrafluorethylene coatings on stainless steel orthodontic wires immersed in tuna fish derived products, Rev.Chim.(Bucharest), 67, no.4, 2016, p.800-807

18. MARECI, D., EARAR, K., ZETU, I., et al., Comparative electrochemical behaviour of uncoated and coated Ni-Ti for dental orthodontic wires, Mat, Plast., 52, no.2, 2015, p.150-153

19. ANTOHE, M.E, FORNA AGOP, D., DASCALU, C.G, Implications of digital image processing in the paraclinical assessment of the partially edentated patient, Rev.Chim.(Bucharest), 69, no.2, 2018 p.521-524 20.POPESCU, E, AGOPFORNA, D, EARAR, K, FORNA, N.C, Bone substitutes used in guided bone regeneration technique review, Mat.Plast, 54, no.2, 2017, pg. 390-392

21. CHECHERITA, L., BELDIMAN, M.A., STAMATIN ,0., et al. Aspects on structure of materials used for different types of occlusal splints. 64(8), 2013,pg.864-867

$\overline{\text { Manuscript received: } 15.02 .2018}$ 